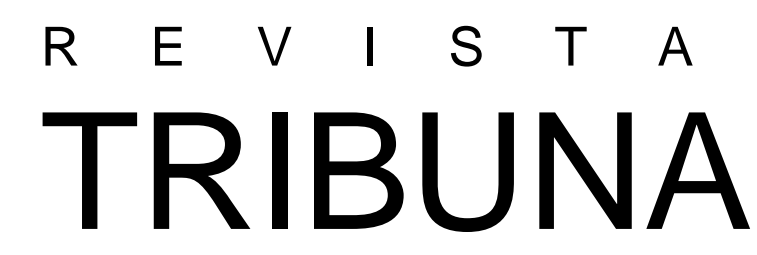

$\frac{\text { INTERNACIONAL }}{\text { Mubr. }}$

Derecho Internacional

Volumen 4 / N 8 / 2015

FACULTAD DE

DERECHO

UNIVERSIDAD DE CHILE 


\section{Rector de la Universidad de Chile}

Ennio Vivaldi Véjar

Av. Alameda Libertador Bernardo O'Higgins 1058, Santiago

\section{Representante legal}

Davor Harasic Yaksic

Decano de la Facultad de Derecho

Universidad de Chile

\section{Director Departamento Derecho Internacional}

Edmundo Vargas Carreño

\section{Director (S) Revista Tribuna Internacional}

Mario Arnello Romo

\section{Editor General Revista Tribuna Internacional}

Luis Valentín Ferrada Walker

\section{Comité Editorial}

Íñigo Álvarez Gálvez (Universidad de Chile, Chile)

Gonzalo Aguilar (Universidad de Talca, Chile)

José Carlos Fernández Rosas (Universidad

Complutense de Madrid, España)

Claudio Grossman (American University, EE.UU.)

Mattias Kumm (New York University, EE.UU.)

Hugo Llanos (Universidad Central, Chile)

Cecilia Medina (Universidad Diego Portales, Chile)

Elina Mereminskaya (Universidad de Chile, Chile)

Mónica Pinto (Universidad de Buenos Aires, Argentina)

\section{Fundador de la Revista Tribuna Internacional}

Mario Ramírez Necochea $†$

\section{Revista Tribuna Internacional M.R.}

Publicación del Departamento de Derecho Internacional de la Facultad de Derecho de la Universidad de Chile. Su objetivo es fomentar la reflexión, el debate, el análisis y la comunicación sobre el derecho internacional en forma pluralista y con rigor científico. Se publica cada semestre en los meses de junio y diciembre mediante convocatoria abierta a la publicación de artículos y monografías inéditos, comentarios de jurisprudencia, recensiones y comentarios de libros, en los campos de derecho internacional público y privado, derecho internacional de los derechos humanos y relaciones internacionales, tanto en castellano como inglés.

La Revista Tribuna Internacional fue creada por Decreto Exento No 8.466 de la Rectoría de la Universidad de Chile, de 22 de marzo del 2011

Volumen 4/ No 8 / 2015

www.tribunainternacional.uchile.cl ISSN 0719-482X (versión en línea)

Departamento de Derecho Internacional Facultad de Derecho Universidad de Chile Av. Santa María 076, $4^{\circ}$ piso Providencia, Santiago de Chile

\section{Diseño y producción:}

Facultad de Derecho

Universidad de Chile

Se autoriza la reproducción total o parcial del contenido de la publicación, siempre que se reconozca y cite el/ la/ los/ las autor/a/es/as y la publicación, no se realicen modificaciones a la obra y no se la utilice para fines comerciales. 


\title{
La función social negativa del derecho de propiedad en sistemas políticos constitucionales y la afirmación popular de los derechos humanos $^{1}$
}

\author{
The negative social function of property in constitutional political systems and the popular \\ affirmation of buman rights
}

\begin{abstract}
Wellington Migliari
wemigliari@yahoo.com.br

Candidato a Doctor en Derecho Internacional Público y Relaciones Internacionales, Derecho y Ciencias Políticas, Facultad de Dret, Universitat de Barcelona, España, y becario de la institución federal brasileña Coordenação de Aperfeiçoamento de Pessoal de Nível Superior (CAPES).
\end{abstract}

\begin{abstract}
Resumen: Con base en el método de derecho comparado, el presente artículo se detiene en el debate de la función social de la propiedad y en su falta de efectividad en dos realidades constitucionales singulares. Teniendo en consideración el caso de desalojo de Pinheirinho, en la ciudad brasileña de São José dos Campos; y el caso español en Tarragona, Cataluña, sobre las cláusulas abusivas en los contratos de propiedad, materias de derechos humanos parecen delimitar cada vez más el escenario legal en defensa de garantías y principios sociales constitucionales. Distintas constituciones revisadas a lo largo del presente trabajo revelan la idea de función social de la propiedad como una experiencia histórica que no se circunscribe solamente a Brasil y España. Para la superación de la inefectiva aplicabilidad de la categoría jurídica debatida sobre propietarios irresponsables, movimientos sociales y acciones afirmativas populares han hecho un esfuerzo para evitar violaciones de derechos humanos en materia de vivienda, aun cuando sus demandas evocan preguntas del debido procedimiento y derecho del consumidor.
\end{abstract}

Palabras clave: Función social de la propiedad - derecho a la vivienda - derechos humanos y movimientos sociales.

\begin{abstract}
According to comparative law method, the present article delves into the social function of property question regarding its ineffectiveness in two different constitutional realities. Taking into consideration the case of eviction, in the Brazilian city of São José dos Campos, area of Pinheirinho; and the Spanish case in Tarragona, Catalonia, about abusive clauses in property contracts, human rights matters are setting the hard law stage for social constitutional principles and guarantees. Different constitutions along the present work emphasise the idea
\end{abstract}

Artículo recibido el 05.10.2015 y aceptado el 10.12.2015. 
La función social negativa del derecho de propiedad

Wellington Migliari

of social function of property as a historical experience not only circumscribed by Spain and Brazil cases. For the ineffectiveness overcoming in the debate about irresponsible proprietors, social movements and popular affirmative actions have made an effort to avoid human rights violations in housing matters, although their demands evoke questions of legal proceeding and consumer protection.

Keywords: Social Function of Property - Right to Housing - Human Rights and Social Movements.

\section{Sistemas constitucionales, función social y conceptos del derecho de propiedad}

La Constitución Federal brasileña de 1988, artículo 5² XXIII; y la española de 1978, artículo 33.2, reconocen la función social de la propiedad. Sin embargo, la ideología parece no interferir en la existencia del dispositivo, tal como parece ser la prerrogativa del Estado social y democrático de derecho. El gobierno del Tercer Reich (1933-1945) mantuvo el concepto de la Constitución de la República de Weimar de 1919, artículo 153, así que el sistema político autoritario no se oponía a la forma jurídica de la función social. En un estado de excepción, selectivo y con probable aplicación pendular de normas sobre derechos de los propietarios, el dispositivo legal y técnico se mantuvo ${ }^{2}$. Como otros países europeos, la sociedad alemana tuvo que hacer frente a abusos económicos y especulativos en el sistema de propiedad con el fin de la Primera Guerra Mundial ${ }^{3}$. Ya contra el poder discrecional y arbitrario del Estado, realidad estadounidense, la Enmienda 5 de 1791 en la Constitución de Estados Unidos de América ha defendido desde su aprobación que no habrá acto de expropiación forzosa sin el debido procedimiento y justa compensación. En el período de reconstrucción que sigue a la Segunda Guerra Mundial, la categoría jurídica se multiplica en diversos contextos nacionales. La Carta italiana de 1947, artículo 42, es un ejemplo. La Constitución de la República Democrática de Alemania de 1949, artículo 22, en este momento, sin explicitar la función social de la propiedad, impone restricciones también al derecho de propiedad cuyos efectos son similares a principios de armonía social en contra el poder absoluto de los propietarios. Es innegable que los sistemas constitucionales europeos comprenden la propiedad privada limitada, pero debe ella y las garantías fundamentales coexistir. El sistema de propiedad genera costes para la justicia de un país, demanda infraestructura y compensación material del Estado hacia al propietario en acciones de expropiación forzosa motivadas por el interés general ${ }^{4}$.

\footnotetext{
SCHIMDT, Carl. "Definición de la soberanía". En: Teología politica. Madrid, Trotta, 2009, pp. 13-20.

WoLF, Nicolaus. "Europe's Great Depression: Coordination Failure after the First World War". Oxford Review of Economic Policy, 2010, vol 26, núm. 3, pp. 339-369.

4 Huffman, James L. "Unconstitutional takings of the private property". En: Private property and the constitution: state powers, public rights and economic liberties. New York, Palgrave, 2013, pp. 139-184.
} 
Revista Tribuna Internacional

Volumen $4 \cdot \mathrm{N}^{\mathrm{o}} 8 \cdot 2015 \cdot$ pp. $185-198$

ISSN 0719-482X (versión en línea)

En el constitucionalismo francés, la Magna Carta de 1958, artículo 34, transfiere la responsabilidad de legislar en materia de propiedad al legislador. Si el parlamento es omiso o negligente frente a principios de una sociedad económicamente justa, hay una transmisión directa de los poderes del legislador para el poder discrecional por parte del ejecutivo. Eso explica la Loi d'Orientation pour la Ville de 1991 (LOV), que imponía un 20\% de vivienda social a cada ciudad y reducción de la segregación espacial. Un mecanismo de contrapoder a cualquier tipo de abuso y noción absoluta del sistema mercadológico en el derecho de propiedad con responsabilidad a ciudades y no a individuos solamente. Están previstas en la Loi Relative à la Solidarité et au Renouvellement Urbains de 2000 sanciones financieras a municipalidades infractoras y incluso la avocación de las competencias para la otorga de licencias de edificación.

Los textos constitucionales pueden indicar brevemente aún definiciones sobre el derecho de propiedad, sus aspectos económicos en el goce de la vida privada y sus fronteras hacia el interés general. El conflicto entre privados también está previsto en principios de inviolabilidad de las garantías fundamentales y, así, es importante la protección del Estado a individuos imposibilitados de acceder a su bien". Sobre el significado de "social" en la función social de la propiedad, también hay matices entre el interés de todos y el pluralismo democrático. Tal como en la Constitución portuguesa de 1974, artículo 61.1, por ejemplo, las restricciones al uso de la propiedad se basan en el interés general y no dispone específicamente de una norma jurídica sobre la función social. Para el constitucionalismo portugués, el bien de los ciudadanos no parte de la lógica de mercado y consumo. Es una noción pionera y fuerte, incluso para obligar al propietario a vigilar su objeto y, consecuentemente, evitar o compensar daños a terceros. En la Constitución de Polonia de 1997, artículo 233.2, los límites a libertades y derechos individuales, tales como propiedad y posesión, no se consideran amenazas al Estado democrático de derecho si no están basados en cuestiones de creencia, género o cualquier otro acto discriminatorio. En los países de Latinoamérica, con sus recientes experiencias en relación con la historia del constitucionalismo, sus cartas nacen del poder constituyente o se modifican a la luz del periodo de redemocratización a partir de los años $1980^{6}$. El sentido social también puede ser la antítesis del proyecto social y económico heredado de la tradición oligárquica en materia de propiedad. El ejercicio político en sus parlamentos conlleva también distorsiones formales, i.e., la función social en el procedimiento judicial es una garantía formal contra abusos del legislador en un congreso con mayoría conservadora y elitista ${ }^{7}$.

El derecho comparado ha sido un área prodigiosa en estudios sobre sistemas constitucionales. Es un método interesante para evidenciar similitudes y contrastes principalmente en elementos

\footnotetext{
"The law does not guarantee me the physical or social ability of actually using what it calls mine. By public regulations it may indirectly aid me by removing certain general hindrances to the enjoyment of property. But the law of property helps me directly only to exclude others from using the things [sic.] which it assigns to me. If then somebody else wants to use the food, the house, the land, or the plow which the law calls mine, he has to get my consent". Vid. CoHEN, Morris R. "Property and sovereignty", Cornell Law Review, 1927, vol 13, núm. 8, pp. 12-13.

6 CRAWFORD, Colin. "The social function of property and the human capacity to flourish". Fordham Law Review, 2011, vol 3, núm. 80, pp. 1089-1134.

7 Simioni, Rafael Lazzarotto. “A sublimação jurídica da função social da propriedade”. Lua Nova, São Paulo, 2006, núm. 66, pp. 109-137.
} 
que no se conectan esencialmente al cotejo de principios o normas per se. En el presente trabajo, pone de relieve contrastes sobre el sentido de "social" en materia de propiedad en cartas constitucionales diversas y permite contrastar decisiones judiciales en realidades sociales y democráticas de derecho muy distintas ${ }^{9}$. Además, el papel de los jueces puede, al mismo tiempo con sus diversas interpretaciones y formas de argumentación, revelar de modo objetivo si decisiones en materia de propiedad promueve más justicia social. Por otro lado, si los magistrados reproducen modelos utilitaristas o consagran una especie de activismo judicial con alto grado de parcialidad ${ }^{10}$. Al comparar decisiones judiciales, sus contrastes y singularidades, o los tipos de técnicas utilizadas en Brasil y España por jueces para resolver la disputa entre propietarios y ocupantes, podemos evaluar qué tipo de democracia ha sido generada. Es posible evaluar también por el método comparado si el sistema de propiedad de cada país ha avanzado o no en temas de derechos humanos internalizados desde sus constituyentes con la ayuda de tratados internacionales. El análisis de fundamentos jurídicos sobre la tensión occupatio y dominium, cosa libre de posesión en caso de omisión especulativa de propietarios-empresas y propiedad absoluta sin obligaciones, también forman parte del poder de policía del Estado ${ }^{11}$.

\section{Caso de Pinheirinho c. Massa Falida Comércio e Indústria Selecta $S / A$ : ¿Inconstitucionalidad en actos administrativos y judiciarios?}

En Brasil, Municipalidad de São José dos Campos, Estado de São Paulo, una propiedad llamada Pinheirinho, que fue ocupada por miembros de la Associação Democrática por Moradia e Direitos Sociais, es un ejemplo claro de negligencia administrativa e incumplimiento de la función social de la propiedad. Se trata de una empresa que ha acumulado numerosas deudas con en el ayuntamiento, el gobierno del Estado de São Paulo y la Federación. Además de la omisión de la responsabilidad del privado, existe la negligencia de poderes públicos locales en no cobrar los impuestos al deudor y, en última instancia, no demandar de estas propiedades irregulares causadoras de estafa a la administración pública el pago forzoso con base en la Ley Federal de Deuda Activa 6.830/1980, artículos $2^{\circ}, \sqrt{ } 1 ; 4^{\circ}, \int 4 ; 6^{\circ}$, apartado I, en materia de equilibrio del presupuesto público. La inacción de la municipalidad corrobora el déficit de vivienda en Brasil y el incumplimiento de límites internos a la propiedad ${ }^{12}$. Conforme al artículo 23, apartado IX, de la Constitución Federal brasileña de 1988 y la Ley Federal

\footnotetext{
ZweIGERT, Konrad; KÖTZ, Hein. "Introduction". En: Introduction to comparative law. 2a ed. Oxford, Clarendon Paperbacks, 1987, pp. 1-12.

9 MacPherson, C. B. "The meaning of property". En: Property: mainstreams and critical positions. Toronto, Blackwell, 1978, pp. $1-13$.

10 ACKerman, Bruce A. "Utilitarian adjudication”. En: Private property and the constitution. New Haven, Yale University Press, 1977, pp. 41-70.

11 HufFman, James L. "Police power". En: Private property and the constitution..., op.cit., pp. 7-44.

12 En el presente caso, la Massa Falida Selecta Comércio e Indústria S/A posee una propiedad en la región sur de São José dos Campos con alto valor inmobiliario-especulativo.
} 
Revista Tribuna Internacional

Volumen $4 \cdot \mathrm{N}^{\mathrm{o}} 8 \cdot 2015 \cdot$ pp. $185-198$

ISSN 0719-482X (versión en línea)

11.977/2009, la responsabilidad de promover viviendas y la regularización del suelo en el país es de todas las competencias administrativas federales, pero con prerrogativa local. Es importante poner de relieve que la Magna Carta brasileña, en materia de propiedad y orden económico, artículo 170, garantiza el derecho de propiedad a empresas en su apartado II, pero alude también a la función social en el apartado III, lo que el patrimonio privado debe tener en cuenta para hacer efectiva la justicia social ${ }^{13}$.

La prioridad constitucional que la municipalidad tiene, previsto en el artículo 182 de la Constitución Federal de 1988, caput, impacta en la política de desarrollo urbano y de planeamiento de las ciudades ${ }^{14}$. Es importante mencionar que la defensa de Pinheirinho es desproporcional y incompatible con los principios constitucionales de equidad. Entre los más de seis mil individuos que vivían en el área y una empresa deudora negligente, de millones de reales en impuesto sobre la propiedad, aparte de la deuda ante sus ex-empleados que generó costes de seguridad social pagados con fondos federales, la solución podría haber sido pensada según el equilibrio de la función social de la propiedad. En 2012, el Tribunal de Justicia del Estado de São Paulo (TJSP) tuvo en sus manos la posibilidad relativa de armonizar el conflicto de intereses entre las competencias administrativas y promover la no polarización entre los propietarios responsables y los que son deudores hacia la sociedad brasileña. Podría también haber hecho más efectivo el derecho a la vivienda e imponer un efecto simbólico en la decisión, por existir una gran movilización de la prensa, la sociedad y las organizaciones de derechos humanos.

En la solución del conflicto, la municipalidad podría haber utilizado el artículo $5^{\circ}$, apartado XXIV, que prevé la indemnización previa y en efectivo para áreas expropiadas con interés social. El coste generado y pagado posteriormente por todos los entes de la Federación fue próximo a tres veces el valor del área de Pinheirinho ${ }^{15}$. Negligencias de las autoridades en

13 Con base en datos del Instituto de Pesquisa Econômica Aplicada (IPEA), hay un déficit de viviendas de 5.4 millones en Brasil. Más de la mitad de las unidades ocupadas, sobre un total de más de 53 millones de hogares en el país, presentan condiciones precarias, con dos o más familias y muchos de los alquileres sobrevalorados. Vid. FurTADO, Bernardo Alves; NeTO, Vicente Correia Lima; KRAuse, Cleandro. "Estimativas do déficit habitacional brasileiro (2007-2011) por municípios (2010)", Nota Técnica, núm. 1, 2013, pp. 5-8. Vid. [en línea]

$<$ http:/ / www.ipea.gov.br/portal/index.php?option=com_content\&view=article\&id=18179> [consulta: 20 de diciembre del 2015].

14 El Estatuto de la Ciudad, Ley Federal 10.257/2001, artículo 39, también prevé la prioridad en materia urbana y la aplicación de la función social de la propiedad para las municipalidades.

15 Una vez el gobierno promueve el Programa Minha Casa, Minha Vida, reglamentado por la Ley 11.977/2009, hay algunos avances importantes. Los grupos familiares en zonas de riesgo geofísico y mujeres responsables de familias monoparentales, grupos previstos en el artículo $3^{\circ}$, apartados II y III, pueden ser entendidos como cambios relevantes. Sin embargo, es necesario aclarar que el proyecto de construcción masiva de viviendas no se inserta en un plano nacional de disminución sistemática de desigualdades. La tensión entre los poderes administrativos empieza en este punto, pues la deuda de propietarios y el incumplimiento constitucional de la función social de la propiedad siguen generando costes en las administraciones públicas. El artículo $2^{\circ}$ de la Ley $11.977 / 2009$, por ejemplo, prevé la viabilidad del programa conforme a la disponibilidad financiera del Estado Federal brasileño. En otras palabras, el coste social para el desarrollo del derecho a la vivienda con construcción de unidades habitacionales, artículo 23, IX, de la Constitución Federal brasileña de 1988, no es tratado como fijo, sino determinado por las variaciones de la contingencia económica e inmobiliaria especulativa. El artículo 21 de texto constitucional brasileño, apartado XX, hace referencia a la construcción de vivienda y a la promoción de políticas de saneamiento básico. No obstante, la construcción de una infraestructura de alcantarillado aún es determinada por la lógica centro-periferia en las ciudades brasileñas. Las regiones más centrales o bien ubicadas en 
materia de salud pública y la falta de infraestructura sanitaria básica forman parte también de las externalidades negativas causadas por la Massa Falida Comércio e Indústria Selecta $S / A^{16}$. Pinheirinho fue devuelto a sus administradores después que el Presidente del TJSP contestara el recurso de los ocupantes ante el poder público federal. Brasil es una federación y el sistema judiciario del gobierno estatal es independiente del poder de las cortes superiores en materia de enjuiciamiento civil. Sin embargo, hay excepciones puntuales. El Superior Tribunal de Justicia, poder federal en los estados, por ejemplo, puede pedir transferencia de competencia en casos de violaciones de derechos humanos.

Irónicamente, hubo noción del error y conflicto en materia de competencia. Según el juez Ivan Ricardo Garisio Sartori, presidente del TJSP, para impedir el reintegro de la posesión, podría el tribunal federal haber acudido al procedimiento correcto. Primero, era necesario que la federación se declarara sujeto pasivo, a saber, afectada por el caso en materia de derechos humanos y obligada indemnizar al propietario por el acto de expropiación forzosa motivado por interés social. De esa manera, el Tribunal Regional Federal tendría competencia para impedir la expulsión violenta de los trabajadores sin techo de Pinheirinho ${ }^{17}$. Conforme a este mismo juez, de acuerdo a los artículos 36, apartado III, y 34, VII, letra b, de la Constitución Federal brasileña de 1988, la justicia de la Federación tenía base legal para evitar el desalojo de aproximadamente 1500 familias. La jueza municipal de la $6^{\mathrm{a}}$ Vara, Márcia Faria Mathey Loureiro, tampoco adoptó esta postura en primera instancia ni impuso el cumplimiento de la función social de la propiedad constitucional ${ }^{18}$. Es importante decir que el conflicto de competencias no es excusa para dejar de considerar la función social de la propiedad y permanecer impasible frente a la incorrección de procedimiento jurídico. Los efectos del desarrollo del caso fueron devastadores para la sociedad brasileña, resultaron en que un privado deudor quedara sin sanciones y motivaron la violencia física y la vulneración de derechos humanos. Los elevados costes a las administraciones promueven más desequilibrio socioeconómico en un país donde hay extremados contrastes sociales ${ }^{19}$. Para el jurista Cândido

el plano urbano de las grandes ciudades brasileñas cumplen relativamente lo que determina la Ley 11.445/2007 en materia de saneamiento básico. Hay todavía un gran número de municipios con enfermedades causadas por falta de condiciones básicas de higiene y salud en Brasil. Los datos oficiales demuestran que más de la mitad de la totalidad de los ayuntamientos en el país sufren con el problema. Son más de 2.400 municipios brasileños afectadas de un total de más de 5.000. En las regiones del nordeste y norte, son los niños quienes se encuentran más expuestos a la falta de servicios básicos.

16 UOL. "Quase 5 milhões de crianças estão expostas a riscos de doenças por falta de saneamento, diz IBGE", 28 de noviembre del 2012, [en línea] <http://noticias.uol.com.br/cotidiano/ultimas-noticias/2012/11/28/quase-5-milhoes-decriancas-estao-expostas-a-riscos-de-doencas-por-falta-de-saneamento-diz-ibge.htm $>$ [consulta: 20 de diciembre del 2015].

17 Vid. la decisión del TJSP de 21 de enero de 2012, [en línea] <http://jornalggn.com.br/sites/default/files/documentos/rodrigocapezpm.pdf> [consulta: 20 de diciembre del 2015].

18 La instancia jurisdiccional de la Unión Federal no demostró interés en el caso durante el año de 2012. Vid. [en línea] <http://www.jfsp.jus.br/assets/Uploads/administrativo/NUCS/decisoes/2012/120123pinheirinho.pdf> [consulta: 20 de diciembre del 2015].

19 KENNEDy, David. "Some caution about property rights as a recipe for economic development". Accounting, Economics and Law, 2011, vol 1, núm. 1, pp. 1-62. 
Revista Tribuna Internacional

Volumen $4 \cdot \mathrm{N}^{\mathrm{o}} 8 \cdot 2015 \cdot$ pp. $185-198$

ISSN 0719-482X (versión en línea)

Rangel Dinamarco, el proceso no debe ser tomado con un fin en sí mismo, sino, sobre todo, como un medio apto para asegurar un derecho invocado, sea por quien fuere ${ }^{20}$.

Ante la clara motivación de interés social presente en la ocupación de Pinheirinho, incluso prevista en el Código Civil brasileño de 2002 , artículo $1.228, \mathbb{\$} 3^{\circ}$, la solución producida fue el desahucio. Además de las consecuencias morales y jurídicas, el Ayuntamiento de São José dos Campos aplicó un descuento de un 10\% sobre los impuestos de la propiedad impagos durante años. Para las tasas futuras sobre la propiedad se aplicó un bono sobre el importe total de un 6,5\%. Antes, el cobro del Impuesto Predial Territorial Urbano era de un 8\%, desde el desahucio, pasó a ser de un 1,5\% ${ }^{21}$. El beneficio de la Massa Falida Comércio e Indústria Selecta $S / A$ se incrementó, porque los gobiernos federal y de la provincia formalizaron un contrato de construcción de viviendas con interés social. Los costes de la indemnización en una nueva área, más la construcción de unidades, superan los 172.8 millones de reales y recaen en toda la sociedad brasileña. El gobierno federal pagará 136.8 millones del total. La deuda sigue subiendo. Once meses después de la ocupación llegó a casi 30 millones de reales ${ }^{22}$. Esa lógica de decisión jurídica estimula las irresponsabilidades de privados y asegura un concepto de propiedad sin ningún tipo de obligación jurídica. Se trata de una propiedad y contratos privados absolutos e imperiosos, sin límites internos y con varias fallas externas por parte del Estado $^{23}$.

El énfasis inicial de la justicia federal en no ver razón para la interferencia del Estado brasileño en la jurisdicción del Estado de São Paulo ha cambiado. Desde la decisión del TJSP de desahuciar a las seis mil personas de Pinheirinho, el magistrado Antônio Cedenho, del Tribunal Regional Federal de la Tercera Región, aceptó el recurso de apelación fundado en que era una materia de derechos humanos y a que debían restablecerse una serie de aspectos relativos al debido proceso y superar los errores del procedimiento a fin de garantizar el derecho de los grupos vulnerables ${ }^{24}$. Según el Informe de la Decisión Nº 13969/2015, el supuesto conflicto de

20 Dinamarco, Cândido Rangel. A Instrumentalidade do Processo. 5a ed. São Paulo, Malheiros, 1996, p. 400.

21 Neto, Moriti. "Pinheirinho: a reurbanização que não houve", Forum, 10 de febrero del 2012, [en línea] <http://www.revistaforum.com.br/2012/02/10/pinheirinho-a-reurbanizacao-que-nao-houve/> [consulta: 20 de diciembre del 2015].

22 "Terreno da Selecta deve pagar sua segunda Dívida na cidade", Guia SJC, 19 de diciembre del 2012, [en línea] <http://www2.guiasjc.com.br/noticias/terreno-da-selecta-deve-pagar-sua-segunda-divida-na-cidade/> [consulta: 20 de diciembre del 2015].

23 Kennedy, Duncan. "Form and substance in private law adjudication”. Harvard Law Review, 1976, núm. 89, pp. 1685-1778. Según el jurista Morton J. Horwitz, la concepción excesivamente física de la propiedad impone una falsa lógica de que un objeto tendrá, entre otros aspectos, un valor de cambio. Si en el contrato no ocurren vicisitudes y todos los procedimientos de mercado están conforme a las reglas de transferencia del bien, es posible que el propietario pueda disfrutar de su objeto. La paradoja de tal razonamiento es que la propiedad puede valorarse o depreciarse conforme a la conveniencia del interés económico y sus cambios. En la tendencia ascendiente o descendiente del valor de la propiedad, la función social o su contribución financiera a los poderes públicos es una forma de compensar la plusvalía que el privado tiene con las inversiones públicas en el alrededor de su bien. Vid. HORWITZ, Morton J. "The progressive transformation in the conception of property". En: The transformation of American law. New York, Oxford University Press, 1992, pp. $145-151$.

24 Recurso de Apelación Instrumental N 0001312-98.2014.4.03.0000/SP. Leonardo Augusto de Andrade Barbosa afirma que las reglas de procedimiento en el período de la constituyente brasileña era una manera de garantizar el equilibrio del Estado de derecho con las fuerzas conservadoras de una sociedad extremadamente tradicional. Vid. BARBOSA, Leonardo Augusto de Andrade. "A emergência do projeto constitucional democrático: convocação, processo e significado da Constituinte de 1987-1988”. En: História constitucional brasileira: mudança constitucional, autoritarismo e democracia no Brasil pós- 
competencia 120789/SP, desahucio de ocupantes y defensa del derecho de propiedad, no invalidan la acción civil pública y la efectividad procesal. Afirma que el poder público federal tiene interés en la solución del conflicto y que el mismo debe apoyar la promoción constitucional de viviendas a grupos marginalizados con base en la Constitución Federal brasileña, artículo 23, apartados IX y X. Menciona el jurista la Ley 11.977/2009, artículos 46 y 50, según los cuales los entes de la administración pública en todos los niveles deben legalizar las ocupaciones con personas que no tuvieron condiciones de elegir otros medios para vivir. El magistrado considera la ocupación en Pinheirinho como legítima, pues no tiene un fin en ella misma y sirve como instrumento paliativo para una solución posterior por parte de los poderes públicos. Las propiedades privadas o del Estado, con características que conforman el perfil de empresas de talante especulativo-inmobiliario, no pueden ser pensadas de la misma manera que los casos de bienes directamente conectados a individuos o familias. Además, el juez federal menciona que los fundamentos de grave violación de derechos de la persona humana están presentes incluso en la resolución de la Corte Interamericana de Derechos Humanos. Antônio Cedenho añade que la Constitución brasileña de 1988, en su artículo 21 letra a, impone la obligación del Estado brasileño en internalizar los principios de la Convención Interamericana ${ }^{25}$.

\section{Caso de Mohamed Aziz c. Caixa d'Estalvis Catalunya: ¿Inconstitucionalidad en actos administrativos y judiciarios?}

El caso Aziz c. Caixa d'Estalvis de Catalunya siguió el mismo curso, pero con extremo valor simbólico. Un señor y su familia, tras años de cumplimiento de sus obligaciones hipotecarias, según la cultura jurídica del derecho de propiedad, debería ir a la calle. Al final, el Tercer Juzgado Mercantil de Barcelona, juez José María Fernández Seijo, planteó al Tribunal de Justicia de la Unión Europea (TJUE) si, bajo un contrato con cláusulas abusivas, una persona tendría como resultado final quedarse sin techo. El TJUE aceptó la demanda de Mohamed Aziz, obrero marroquí, y las consecuencias jurídicas para el Estado español fueron numerosas. Primero, el hecho de estar obligado a cambiar su cultura jurídica de desahuciar sin imponer restricciones al uso mercadológico de la propiedad privada. Después, había una cuestión de derecho del consumidor. Así, la buena fe y condiciones de pago también deben ser propuestas por el consumidor. La base legal se encuentra en el artículo $3^{\circ}$, caput, y su apartado primero de la Directiva 93/13 de la Comunidad Económica Europea. Tercero, que el cumplimiento de un

1964. Brasília, Edições Câmara, 2012, pp. 238-247.

25 En 2007, el Estado brasileño fue condenado por la Corte Interamericana de Derechos Humanos, caso 12.478, Sétimo Garibaldi, por la violación de los artículos $8^{\circ}$ y 25 de la Convención Americana, sobre garantías y protección judiciales. Vid. [en línea]

<http://www.cidh.oas.org/demandas/12.478\%20Setimo\%20Garibaldi\%20Brasil\%2024\%20diciembre\%202007\%20ESP. pdf> [consulta: 20 de diciembre del 2015]. 
Revista Tribuna Internacional

Volumen $4 \cdot \mathrm{N}^{\circ} 8 \cdot 2015 \cdot$ pp. $185-198$

ISSN 0719-482X (versión en línea)

derecho privado o surgido de un contrato no puede afectar a un principio constitucional. La materia debe ser analizada a la luz de valores provenientes de la dignidad y la protección humana, no por la lógica del mercado y el ánimo de lucro. En España, bancos, grandes promotores de vivienda y agencias gestoras de inmuebles siguen elevando sus beneficios materiales con el mercado de propiedades. Propietarios de tal naturaleza han sobrecargado el acceso a la justicia para someter a juicio a los menos favorecidos más que, realmente, para negociar con ellos. A pesar de ser una tensión muy dura, tal conflicto ha cuestionado al Estado español. Ha suscitado a la vez otros derechos sociales e impulsado más efectividad para el derecho a la vivienda digna y asequible. No obstante, hay todavía retos.

El artículo 148.3 de la Constitución española de 1978 atribuye las materias de planificación del suelo edificable a las Comunidades Autónomas. La ordenación del territorio, urbanismo y vivienda son competencias de las regiones y no del Estado español. Sin embargo, los estatutos aprobados en parlamentos locales no deben generar conflictos con derechos y principios constitucionales. Según Javier Pérez Royo, dicha desconexión entre derechos constitucionales y leyes orgánicas, en consecuencia, con los estatutos autonómicos, "choca con la finalidad perseguida por el legislador, que no era otra que la de integrar a las Leyes Orgánicas en una suerte de "bloque de constitucionalidad" ${ }^{26}$. Si consideramos el problema desde la perspectiva del derecho público, tampoco los decretos autonómicos pueden amenazar a normas que tienen como fin la buena administración. Incluso el Consejo de Europa, con la recomendación R(2007)07, documento aprobado por su Consejo de Ministros, ha puesto de relieve la responsabilidad de las administraciones y las competencias que tienen respecto a un gran número de individuos y al interés general. La negociación de viviendas de protección oficial en régimen de mercado con ánimo de lucro es un ataque a los recursos provenientes de los ciudadanos, a los derechos sociales considerados en la Constitución y a la buena administración. Sobre el caso de Mohamed Aæiz c. Caixa d'Estalvis de Catalunya, el juez catalán del Tercer Juzgado Mercantil de Barcelona tuvo especialmente en cuenta la demanda de derecho a la vivienda a la luz de tratados internacionales y, consecuentemente, aseguró un derecho constitucional.

La decisión del juez José María Fernández Seijo de consultar al TJUE fue una alternativa que no se frenó por los posibles errores de procedimientos. Es importante mencionar que la demanda del afectado Mohamed Aziz en contra de la Caixa d'Estalvis de Catalunya no llegó a él como un problema puramente de derecho de consumidor. No obstante, el juez tenía claro que plantear el caso o darle una solución solo en el campo de los derechos humanos no resultaría en una decisión efectiva. La cultura de poderes absolutos de la propiedad es aún muy fuerte en España. Además, para el magistrado, era necesario el cambio en la lógica jurídica y pensar el problema del derecho a la vivienda por medio del contexto social y actual de crisis en

26 PÉREz Royo, Javier. "La constitución como fuente de derecho". En: Las fuentes del derecho. 5a ed. Madrid, Tecnos, 2007, pp. 29-56. 
el sistema hipotecario ${ }^{27}$. Parámetro este inclusive en conformidad con el Código Civil español, artículo 3.1, i.e., "Las normas se interpretarán según el sentido propio de sus palabras, en relación con el contexto, los antecedentes históricos y legislativos y la realidad social del tiempo en que han de ser aplicadas". Es importante decir que la actitud del magistrado en el caso de Mohamed Aziz reveló un fortalecimiento de los valores y principios de garantías fundamentales, pero, por sobre todo, de una ética basada en la dignidad de la persona humana reconocida por la Constitución española de 1978. Después que el TJUE dictó su parecer, hubo un cambio colosal en las decisiones de los jueces españoles en cuanto al conflicto entre el sistema de propiedad y el derecho a la vivienda. Actualmente, los bancos son los mayores propietarios en el Estado español e incumplen normativas locales, como la 18/2007 de Cataluña, al mantener pisos y viviendas desocupadas por más de dos años ${ }^{28}$.

\section{La negativa función social de la propiedad, vivienda y derechos humanos}

La negación de la función social de la propiedad descrita en el presente trabajo se concreta en el momento en que tanto las administraciones públicas como el poder judicial son negligentes en materia de garantías sociales. El conflicto entre el derecho a la vivienda y el sistema de propiedad bajo una interpretación favorable al interés social es negado en realidades con enormes contrastes socioeconómicos. Los costes creados por la enorme cantidad de procesos en la justicia y contra el patrimonio de las administraciones públicas son altos. No obstante, podemos ser optimistas respecto al cumplimiento de los derechos básicos de ciudadanía, con una base jurídica fundada en los tratados internacionales. La Constitución de la República de la Nación Argentina de 1994 no reconoce la función social de la propiedad, pero, en su artículo 75, apartado XXIII, afirma que corresponde al Congreso "legislar y promover medidas de acción positiva que garanticen la igualdad real de oportunidades y de trato, y el pleno goce y ejercicio de los derechos reconocidos por esta Constitución y por los tratados internacionales vigentes sobre derechos humanos" ${ }^{29}$. Argentina es signataria de la Convención Americana de Derechos Humanos (CADHs) y, en su artículo 21, la propiedad tiene su uso subordinado al interés social. En Latinoamérica, el interés general y la función social de la propiedad están presentes en otros textos constitucionales y amparados por la CADHs. En la Constitución de

27 Estapa, J. S.; Perez, Jordi Bonet (Eds). El Derecho internacional de los derechos bumanos en periodos de crisis. Barcelona, Marcial Pons, 2013, p. 323.

28 El Instituto Nacional de Estadística (INE) publicó una nota en diciembre de 2013 sobre el número de viviendas desocupadas en España. Son más de 3.4 millones de unidades subutilizadas y que incumplen la función social de la propiedad. Vid. [en línea] < http://www.ine.es/censos2011_datos/cen11_datos_inicio.htm> [consulta: 20 de diciembre del 2015].

29 La Constitución de la Nación Argentina de 1949, artículo 38, tenía la función social de la propiedad como reto para establecer el bien común. 
Revista Tribuna Internacional

Volumen $4 \cdot \mathrm{N}^{\circ} 8 \cdot 2015 \cdot$ pp. $185-198$

ISSN 0719-482X (versión en línea)

la República de Uruguay de 1967, artículo 32, la propiedad debe tener también en cuenta las leyes posteriores y derivadas del principio de interés general en materia de desarrollo socioeconómico. En el artículo $6^{\circ}$ se garantiza la solución de conflictos siempre basados en la integración social y económica. La Constitución Política del Estado Plurinacional de Bolivia de 2008, artículo 56, I, reconoce la función social de la propiedad y establece una estructura más compleja para la categoría jurídica. Avanza, por ejemplo, en la jurisdicción agroambiental, artículo 186; recursos hídricos, artículo 373, II; y propiedad agraria, artículo 397, I y II. Es evidente que los contrastes sociales y la creciente concentración de renta en los países latinoamericanos forman todavía parte de sus complejas realidades, pero pueden ser combatidos con el uso más equilibrado del sistema de propiedad. El derecho a la vivienda parecer ser una buena traducción jurídica de la función social.

La discusión sobre el derecho a un hogar es distinta que la efectiva promoción del derecho a la vivienda digna y asequible. No es un concepto reciente y ya en el artículo 11.3 de la Constitución de Austria de 1920, la legislación federal preveía la relación entre viviendas con interés social y la dignidad humana. Los conflictos armados del siglo XX dejaron miles de muertos, pero también sensibilizaron a los poderes públicos. El avance del capital inmobiliario en Europa en la era posterior a la Primera Guerra Mundial (1914-18) era una realidad y debería ser frenado en el contexto de reconstrucción. Por eso, el ánimo de lucro y el mercado existen, pero de manera moderada en formas de fondos sociales. La Constitución italiana de 1947, artículo 47, por ejemplo, prevé el ahorro popular para el crédito y la financiación de viviendas. Sin perjuicio de los numerosos problemas, había un esfuerzo conjunto para la edificación de una sociedad más justa en la época posterior a la Segunda Guerra Mundial (1939-45). La Constitución de Alemania de 1949 afirma, artículo 26, que cada ciudadano o familia, principalmente, víctimas del nazismo o la guerra, tiene derecho a una vivienda digna. La Constitución de Polonia de 1997, artículo 75.1, asegura lo mismo. El derecho a la vivienda es un mecanismo objetivo y presente también en los países que pasaron por experiencias de gobiernos autoritarios amparados por regímenes de excepción como España, Portugal, Grecia y Brasil, así como el nazi-fascismo en Italia y Alemania. La Constitución de España de 1978, artículo 47, y la Constitución Federal brasileña de 1988, artículo $6^{\circ}$, asocian la vivienda digna a otros derechos tal como al agua potable o el derecho a un medio social no degradante, e integrada a la infraestructura urbana. En el plano internacional, este principio auxilia al esfuerzo de superación de condiciones de vida deplorables en las grandes ciudades globales. La función social se muestra compatible con el sistema de propiedad y el derecho a la vivienda.

En los últimos años, el Comité Europeo de Derechos Sociales ha preparado el camino para la jurisprudencia en materia de vivienda como los casos concretos de desahucios de Centre on Housing Rights and Evictions v. France, Italy and Croacia. Los documentos 63/2010, 58/2009 y $52 / 2008$ son muy relevantes ${ }^{30}$. El artículo 31 de la Carta Social Europea reafirma la

30 Vid. los artículos $2^{\circ}$ y $8^{\circ}$ del Convenio para la Protección de los Derechos Humanos y de las Libertades Fundamentales de 1950. La Corte Europea de Derechos Humanos defiende el derecho de cada ciudadano víctima de violación de derechos 
La función social negativa del derecho de propiedad

Wellington Migliari

importancia de defensa de este derecho como una forma de combate contra la pobreza, exclusión y vulnerabilidad de los grupos marginalizados. En noviembre de 2014, en una resolución de Council of Europe, European Committee of Social Rights, España fue también condenada por incumplir derechos fundamentales y por poner en riesgo la dignidad humana en materias como trabajo, derecho a la organización colectiva y a la justa remuneración salarial $^{31}$. Otros países también han vulnerado a la clase trabajadora sin imponer responsabilidades a los sistemas de propiedad. La Fédération Européenne des Associations Nationales Travaillant avec les Sans-Abri (FEANTSA) ha litigado con el gobierno francés en cuestiones de conflicto e inefectividad del derecho a la vivienda. La organización demandó a Eslovenia y Holanda por el mismo motivo. Los casos 30/2006, CC39/2006 y 86/2012 muestran ejemplos de Estados que no cumplen con el equilibrio social imponiendo límites a los grandes propietarios de viviendas, privados o públicos, y que son negligentes frente al interés genera ${ }^{32}$. Hay decisiones judiciales que reflejan formas tradicionales de poder en el orden burgués y que mantienen relaciones de privilegio claramente bajo una noción de derecho civil. Tal cooptación es incompatible con los preceptos constitucionales por más justicia social y económica en los Estados contemporáneos post-dictaduras de los años 1970 y $1980^{33}$. La negación del precepto de la función social de la propiedad está presente en la tradición ibérica en cuanto a lo que las clases políticas y financieras más poderosas comprenden por propiedad privada ${ }^{34}$.

\section{Breves notas finales sobre la afirmación popular de los derechos humanos}

En 1832, los trabajadores de Londres hicieron un huelga general por un mes. La denominaron periodo de vacaciones para todos: "During this 'holiday' period, working-class representatives would draw up a constitution to 'place every human being on the same footing. Equal rights, equal enjoyments, equal toil, equal respect, equal share of production" ${ }^{35}$. Los operarios luchaban por más derechos y eso tenía que ver con la noción más o menos actual de ciudadanía en un Estado democrático y social de derecho. Sin embargo, es importante destacar

humanos. La Carta Social Europea, Consejo de Europa, afirma el derecho a la vivienda en varias secciones de su documento. Parte I, $\int 31$; artículos 15.3; 16, 23 y 30.

31 European CommitTeE OF Social Rights. "Conclusions XX-2 (Espagne). Articles 3, 11, 12,13 and 14 of the 1961 Charter", [en línea] <http://www.idhc.org/arxius/noticies/1418903800-SpainXX2_en.pdf> [consulta: 20 de diciembre del 2015].

32 Las Observaciones Generales N 4 y 7, del Comité de las Naciones Unidas para los Derechos Económicos, Sociales y Culturales, reconoce que sigue existiendo un abismo entre lo que afirma el texto del Pacto Internacional de Derechos Económicos, Sociales y Culturales de $1966, \int 1^{\circ}$, artículo 11 , y la realidad de todos los continentes en materia de vivienda como un derecho humano.

33 Hespanha, A. M. “La revolución y los mecanismos del poder (1810-1851)". En: Derecho privado y revolución burguesa. Madrid, Marcial Pons, 1990, pp. 15-51.

34 Rey MARTíneZ, Fernando. La propiedad privada en la Constitución Española. Madrid, Boletín Oficial del Estado, 1994, p. 464.

35 Rosenberg, David. "Rebellious city: London from the 1830s to the 1930s". En: Rebel footprints: a guide to uncovering London's radical history. London, Pluto Press, 2015, pp. 7-18. 
Revista Tribuna Internacional

Volumen $4 \cdot \mathrm{N}^{\mathrm{o}} 8 \cdot 2015 \cdot$ pp. $185-198$

ISSN 0719-482X (versión en línea)

que "There is, for this reason, a dissident and influential view of the Commune that says it was not a proletarian uprising or a class-based movement at all, but an urban social movement that was reclaiming citizenship rights and the right to the city. It was not, therefore, capitalist ${ }^{336}$. Actualmente, la afirmación de lo que entendemos como más derechos hacia la persona humana, para la clase trabajadora del siglo XIX en Inglaterra y Europa continental, pasaba por una decisión política y no necesariamente por una reducción analítica cargada de clichés sobre la lucha de clases. Es factible afirmar que había una estrategia política organizada, pero, sobre todo, motivada por una pluralidad de sentimientos ciudadanos ${ }^{37}$. Las estructuras constitucionales del siglo XX y las más recientes en Latinoamérica pueden ser evidenciadas en un nuevo constitucionalismo ciudadano ${ }^{38}$. El derecho a la vivienda, impulsado por demandas que suscriben materias de derechos humanos, son capaces de hacer más efectiva la función social de la propiedad que, en su historia, tuvo escaza aplicación objetiva ${ }^{39}$. El derecho a renta básica, vivienda digna y asequible, a la protección individual y familiar, a las libertades económicas y a políticas de ayuda a minorías, son temas esenciales para un derecho internacional más humano ${ }^{40}$. Destacamos en nuestro caso los movimientos sociales como plataformas críticas empoderadas y observadoras del trabajo jurídico-administrativo de sociedades como Brasil y España.

El Movimento dos Trabalhadores Sem-Teto, la Frente de Luta por Moradia y la União dos Movimentos de Moradia son algunos de los ejemplos en la lucha por más derechos a la vivienda como la Associação Democrática por Moradia e Direitos Sociais en nuestro estudio de caso. Derechos constitucionales considerados esenciales para ciudadanos de grandes ciudades, el derecho de ir y venir, por ejemplo, también está presente en demandas como la que presenta el Movimento Passe Livre sobre cuestiones de movilidad urbana y las periferias de la ciudad de São Paulo. Resistir y ocupar los espacios públicos por más dignidad humana por parte de las comunidades que defienden las uniones homoafectivas, Associação da Parada do Orgulho de Gays, Lésbicas, Bissexuais e Transexuais, forman parte de la lucha por más derechos y ciudadanía en materia de derechos humanos. El método de los movimientos sociales actuales, no restringidos a materias de la función social de la propiedad, es mencionar el parámetro constitucional y exponer, así, la primera noción de legalidad a la sociedad en general. La toma de decisión y su influencia son objetos cada vez más importantes para grupos marginalizados ${ }^{41}$. El caso de España empieza

36 HARVEY, David. "Reclaiming the city for anti-capitalist struggle". En: Rebel cities: from the right to the city to the urban revolution. London, Verso, 2012, pp. 115-154.

37 SouZA, M. L. de. "Which right to which city? In defence of political-strategic clarity", Interface: a Journal for and about Social Movements, 2010, 1(2), pp. 315-333.

38 MAMAni, Juan Ramos. "Nuevo constitucionalismo social comunitario desde América Latina". En: Novo constitucionalismo latino-americano: o debate sobre novos sistemas de justiça, ativismo judicial e formação de juízes. (Coord.) MORAIs, Jose Luis Bolzan; Barros, Flaviane de Magalhães. Belo Horizonte: Arraes, 2014, pp. 1-17; BrennER, N.; MArcuse, P.; MAYER, M. Cities for people, not for profit: critical urban city and the right to the city. New York, Routledge, 2012.

39 CunHA, Alexandre dos Santos. "The social function of property in Brazilian law". Fordham Law Review, 2011, núm. 80, pp. 1171-1181.

40 Kenna, Padraic. Los derechos a la vivienda y los derechos humanos. Terrassa, ProHabitatge, 2006, p. 255.

41 La discusión por más derechos en el contexto de las ciudades generó la tesis de Henri Lefebvre sobre el derecho de individuos y trabajadores al espacio urbano. Su obra seminal es El derecho a la ciudad, de fines de los años 1960. Sin embargo, es en el larguísimo ensayo La producción del espacio que temas como el valor de uso y de cambio, el fetichismo del 
La función social negativa del derecho de propiedad

Wellington Migliari

con la Plataforma de Afectados por la Hipoteca y la crisis de 2008 por toda Europa. En Inglaterra, la Radical Housing Network Organisation conceptualiza y defiende que "A decent home should be physically comfortable; be secure; have access to schools; work; healthcare; cultural facilities; transport; fresh affordable food and green space; allow people to have control over their indoor and outdoor environment; be genuinely affordable, allow people to develop communities and support each other". Son numerosos los parámetros que representan técnicamente principios constitucionales. Así como la Plataforma de Afectados por la Hipoteca, los movimientos luchan por una solución más valiente del Estado a fin de solucionar el conflicto entre el sistema de propiedad inmobiliario-especulativo y el derecho a la vivienda en Brasil. La sociedad civil organizada en distintos continentes ha visto de manera crítica el mercado abusivo de alquileres y la función mercadológica del derecho de propiedad: "rising costs of housing; sell-off of council housing; encouragement of profiteering, speculation and buy-to-let; increase in overcrowding and street homelessness; destruction of housing coops; and other social housing solutions; criminalisation of squatting; welfare reform policies; reduction of security; increasing eviction and displacement; empty homes; decreasing quality of housing; gentrification and displacement" ${ }^{\prime 42}$.

espacio, urbanismo y mercancía, pueden ayudar la discusión de los derechos humanos y a la búsqueda por más participación colectiva en las urbes. Además, las consecuencias negativas del urbanismo técnico y la división internacional de trabajo están apoyadas en su estudio filosófico e histórico en densas reflexiones sobre modelos de ciudades aún actuales. Vid LeFEBvre, Henri. La producción del espacio. Madrid, Capitán Swing, 2013, p. 451.

42 RAdical Housing NETWORK. "About”, [en línea] <http://radicalhousingnetwork.org/about/principles-2/> [consulta: 20 de diciembre del 2015]. 